\title{
A Rapid and Efficient Protocol for Adventitious Shoot Regeneration and Genetic Transformation of Manchurian Ash (Fraxinus mandshurica Rupr.) using Hypocotyl Explants
}

Lin Liu

Northeast Forestry University

Yang Cao

Northeast Forestry University

Yaguang Zhan

Northeast Forestry University

Fenghui Qi ( $\square$ qifenghui2001@126.com )

Northeast Forestry University https://orcid.org/0000-0002-2531-2479

\section{Research article}

Keywords: Adventitious shoots, Fraxinus mandshurica, hypocotyl explants, tissue culture, Agrobacteriummediated transformation

Posted Date: September 17th, 2020

DOI: https://doi.org/10.21203/rs.3.rs-60987/v1

License: (9) This work is licensed under a Creative Commons Attribution 4.0 International License.

Read Full License 


\section{Abstract}

Background: Manchurian ash (Fraxinus mandshurica Rupr.) is an endangered hardwood tree species, providing both economic and medicinal benefits. However, observations such as browning of adventitious shoot buds and high rate of somatic embryo abnormality, were presented in protocols of $F$. mandshurica regeneration. Therefore, a rapid and high-efficiency regeneration system is demanded for mass propagation and genetic transformation of F. mandshurica.

Results: We have developed an efficient regeneration system through adventitious shoot organogenesis in F. mandshurica using hypocotyl explants, with which the adventitious shoots are able to elongate and were obtained in an affordable time. Hypocotyls excised from embryos were pre-cultured in the dark on woody plant medium (WPM) supplemented with $6 \mathrm{~g} \mathrm{~L} \mathrm{-1} \mathrm{potassium} \mathrm{citrate,} \mathrm{and} \mathrm{then} \mathrm{inoculated} \mathrm{on} \mathrm{WPM}$ medium supplemented with different concentrations of plant growth regulators (PGRs) to induce adventitious shoot bud formation. The induction medium supplemented with a single PGR of $1.0 \mathrm{mg} \mathrm{L}-1$ thidiazuron (TDZ) was the best treatment, showing $86.67 \%$ shoot bud induction with a 15 -day initial dark culture, followed by culture under a low light condition. The survival rate of regenerated shoot buds reached $70.97 \%$ on WPM medium supplemented with $0.025 \mathrm{mg} \mathrm{L}-1$ TDZ and $1.0 \mathrm{mg} \mathrm{L}-1$ gibberellic acid (GA3). Based on this regeneration system, By using the sonication plus vacuum-infiltration method,a protocol for Agrobacterium tumefaciens -mediated transformation of hypocotyls was established,the transformation rate was determined to be $3.57 \%$.

Conclusions: Key factors, such as the potassium citrate pretreatment, wound treatment on explants, variable light conditions, and significant PGR interactions, were revealed to affect the induction and elongation of adventitious shoots from F. mandshurica hypocotyls in this study. The adventitious shoots, tissue culture plantlets, and rooted plantlets were obtained at 40, 80-100, and 160 days, respectively. This regeneration system shortens the period of traditional regeneration methods, which require months to induce callus from leaves or stems, and additional several months for organ differentiation. In addition, the Agrobacterium-mediated transformation protocol established on the basis of this regeneration system provides a foundation for breeding, genetic improvement and genomic studies of $F$. mandshurica.

\section{Background}

Manchurian ash, Fraxinus mandshurica Rupr. (family Oleaceae), is a species of Fraxinus native to northeastern Asia in northern China (Gansu, Hebei, Heilongjiang, Henan, Hubei, Jilin, Liaoning, Shaanxi, and Shanxi Province), Korea, Japan, and southeastern Russia[1]. It is a large deciduous tree reaching $30 \mathrm{~m}$ tall or above (the tallest one reaches beyond $35 \mathrm{~m}$ ), with a straight trunk up to $2 \mathrm{~m}$ in diameter. $F$. mandshurica is tolerant of many soil conditions and does not require particular soil pH except for showing poor growth at high $\mathrm{pH}$. It is occasionally cultivated as an ornamental tree in parts of Canada and the United States. F. mandshurica is widely used for furniture and special building materials because of its good timber quality and beautiful texture. However, adult trees of $F$. mandshurica are rarely found to spread across large areas due to long-term overexploitation and widespread deforestation. $F$. 
mandshurica is now a threatened species and has therefore been declared a national endangered tree species in China [2, 3]. F. mandshurica is also a commonly used species for afforestation. It can form a mixed coniferous-deciduous forest with a variety of coniferous and broad-leaved trees, which is conducive to improving the stability of the forest ecosystem [4].

The propagation of $F$. mandshurica mainly relies on seeds, which can be produced from seed banks or excellent strains for seedling nursery and afforestation. However, it takes approximate 20 to 30 years for F. mandshurica to grow from seedlings to adult trees, and another 3 to 5 years for adult $F$. mandshurica to bloom and bear fruit once or twice. Low rates of pollen formation and dispersal due to low efficiency of fertilization and rainfall, as well as the delayed flowering caused by low temperature, greatly affected the fruit set rate of $F$. mandshurica. In addition, seeds of $F$. mandshurica have the characteristics of hard pericarp, thick waxy layer, high oil content, deep dormancy, low germination and propagation rates [5]. $F$. mandshurica seed germination must undergo a vernalization treatment for up to 6 months [6], otherwise it takes two to three years for natural germination. Taken together, these increase the difficulty of $F$. mandshurica seedling raising and limit its reproduction in forest development $[7,8]$. During the grafting process, the degree of joining between scions and rootstocks, the quality of scions, and the method of grafting all affect the final survival rate of $F$. mandshurica [9]. Studies on tissue culture of $F$. mandshurica, such as callus culture[10], somatic embryogenesis [11-13], and axillary bud proliferation[14], all demonstrated certain limitations including high rates of adventitious buds browning and somatic embryo deformity, and low rate of shoot elongation. A variety of materials including the vegetative organs and reproductive organs of Fraxinus mandshurica are cultivated, but the best results can only obtain the growth of a single bud, and have not obtained any hyperplastic plants[12].Genetic engineering technologies provide an attractive way to effectively improve current varieties of $F$. mandshurica[15]. However, the low regeneration efficiency has always led to the failure of obtaining transgenic plantlets. Therefore, it is urgent to establish a rapid and high-efficiency regeneration system of $F$. mandshurica.

Flowering time of plants is a complex physiological response induced by various environmental signals. The proteins encoded by LIGHT-REGULATED1 (LWD1) and LWD2 genes play a crucial role in the photoperiodic pathway for flowering time control in Arabidopsis[16]. However, there are currently very limited reports on the genes related to flowering time in F. mandshurica, and no report on successful genetic transformation of $F$. mandshurica. Therefore, we aim to (1) establish a rapid, high-efficiency, and cost effective regeneration system of $F$. mandshurica, (2) develop a protocol for genetic transformation of the $F m L W D 1$ gene in $F$. mandshurica by taking advantage of the regeneration system.

\section{Results}

\section{Induction of adventitious shoot buds from hypocotyls}

Six introduction media with different combinations of 6-benzyladenine (BA) and thidiazuron (TDZ) were tested (Table 1). After incubation in the dark for 5 days, visible protuberances were formed on most hypocotyl explants (Fig. 1a-f), with relatively more protuberances on those hypocotyls pre-treated with 
potassium acid (Fig. 1g). However, explants without hypocotyls produced no protuberance except for the enlargement in size (Fig. 1h). After 11 days, protuberances and multiple Y-shape outgrowths, which subsequently developed into adventitious shoots, were observed on all hypocotyl explants (Fig. 2a). While those radicle (entire or partial) explants produced only calluses that were white, transparent, globular, and loose (Fig. 2h). Explants were then cultured under light conditions after 15 days due to some protuberances were observed in vitrification.

Table 1

Effect of Plant growth regulator on adventitious shoots regeneration from hypocotyls of Fraxinus mandshurica

\begin{tabular}{|llll|}
\hline Medium number & PGR $(\mathrm{mg} / \mathrm{L})$ & Hypocotyl \\
\hline & TDZ & BA & Shoot formation (\%) \\
\hline WY1 & 0.4 & & $37.50 \pm 12.50$ \\
\hline WY2 & 0.6 & $63.33 \pm 5.77$ \\
\hline WY3 & 0.8 & $56.67 \pm 5.77$ \\
\hline WY4 & 1.0 & & $82.22 \pm 5.88$ \\
\hline WY5 & 0.08 & 1.0 & $80.00 \pm 10.00$ \\
\hline WY6 & 0.8 & 1.0 & $63.33 \pm 5.77$ \\
\hline N-WY4 & 1.0 & & $86.67 \pm 5.77$ \\
\hline N-WY4: explants were pretreated with potassium citrate for 5 days before inoculated on WY4 medium \\
\hline
\end{tabular}

Although all combinations of BA and TDZ in the induction medium showed some level of adventitious shoot bud formation on hypocotyls, the response of hypocotyl explants was variable based on the relative concentrations of the two PGRs (Table 1). The percent of explants with shoot bud induction ranged from $37.50-82.22 \%$ on media containing TDZ and zero BA, and increased with an increase in TDZ concentration (Table 1). While an opposite was observed for media supplemented with $1.0 \mathrm{mg} \mathrm{L}^{-1}$ BA and TDZ of various concentrations (Table 1). With comparison of the germination rates, a significant difference ( $P=0.009$ ) was observed among TDZ concentrations, indicating that TDZ is a significant factor in adventitious shoot bud formation from hypocotyls of $F$. mandshurica. We also compared the germination rates between explants pretreated with and without potassium citrate (Table 1), and found, however, no significance $(P=0.634)$.

Both buds (Fig. 3a) and hypocotyls (Fig. 3b) began to turn red after being cultured under light with an intensity of $80 \mu \mathrm{mol} \mathrm{m} \mathrm{m}^{-2} \mathrm{~s}^{-1}$ for 3 days. Given the observation of compact calluses (Fig. 3b), we reduced the light intensity to $10 \mu \mathrm{mol} \mathrm{m} \mathrm{m}^{-2} \mathrm{~s}^{-1}$ because strong lights may promote the aging of hypocotyls. The buds then turned to green as a consequence, and formed adventitious shoots at around 20 days (Fig. 3c, d). The callus continued expanding (Fig. 3d) even cultured under low light conditions, probably due to 
having been incubated under strong lights at an early stage. To confirm this, we cultured the hypocotyl explants, which having been incubated in the dark for 15 days, under low light condition for 20 days, and found no callus was produced (Fig. 4a).

\section{Elongation And Transplanting Of Adventitious Shoots}

The explants with adventitious shoots (Fig. 4a) were transferred to elongation media and cultured for 30 days. Eight elongation media with different combinations of PGRs were tested in this study (Table 2). To better elucidate which medium would produce a higher percentage of shoot elongation, we present the percent shoot elongation and percent explant survival (Table 2). The medium supplemented with $0.025 \mathrm{mg} \mathrm{L}^{-1} \mathrm{TDZ}$ and $1.0 \mathrm{mg} \mathrm{L}^{-1}$ gibberellic acid (GA3) proved to be the best elongation medium overall. Even though the percent explant survival (53.33\%) appears low, this medium produced the highest percentage (53.33\%) of shoots able to elongate (Fig. 4b). On media with higher explant survival rates (medium supplemented with $0.6 \mathrm{mg} \mathrm{L}^{-1} \mathrm{TDZ}$ and $1.0 \mathrm{mg} \mathrm{L}^{-1}$ naphthaleneacetic acid (NAA), and medium supplemented with $0.025 \mathrm{mg} \mathrm{L}^{-1} \mathrm{TDZ}$ and $0.6 \mathrm{mg} \mathrm{L}^{-1} \mathrm{BA}$ ), the shoots either produced callus that inhibited the elongation, or grew leaves (Fig. 4d). In comparison of the elongation and survival rates of adventitious shoots, a significant difference $(P=0.029)$ was observed among media with different PGR combinations, indicating that PGR interactions can affect the activity of adventitious shoots during the first round elongation.

Table 2

Effect of Plant growth regulator on shoots elongating

\begin{tabular}{|c|c|c|c|c|c|c|}
\hline \multirow[t]{2}{*}{ Medium number } & \multicolumn{4}{|c|}{ PGR (mg/L) } & \multirow[t]{2}{*}{ Elongation rate(\%) } & \multirow[t]{2}{*}{ Survival rate(\%) } \\
\hline & TDZ & GA3 & BA & NAA & & \\
\hline $\mathrm{A} 1$ & 0.025 & 1.0 & & & $53.33 \pm 23.09$ & $53.33 \pm 11.55$ \\
\hline A2 & 0.05 & 1.0 & & & $33.33 \pm 23.09$ & $33.33 \pm 23.09$ \\
\hline A3 & 0.05 & 2.0 & 0.6 & & $40.00 \pm 20.00$ & $20.00 \pm 34.64$ \\
\hline A4 & 0.05 & 2.0 & & & $40.00 \pm 34.64$ & $26.67 \pm 30.55$ \\
\hline A5 & 0.025 & & 0.6 & & $46.67 \pm 30.55$ & $66.67 \pm 30.55$ \\
\hline A6 & 0.025 & & 1.5 & & $26.67 \pm 11.55$ & $46.67 \pm 30.55$ \\
\hline A7 & 1.0 & & 5.0 & & $13.33 \pm 11.55$ & $33.33 \pm 11.55$ \\
\hline A8 & 0.6 & & & 1.0 & $13.33 \pm 11.55$ & $73.33 \pm 11.55$ \\
\hline
\end{tabular}

All survived explants from the first-round elongation were therefore transferred on the best elongation medium (with $0.025 \mathrm{mg} \mathrm{L}^{-1} \mathrm{TDZ}$ and $1.0 \mathrm{mg} \mathrm{L}^{-1} \mathrm{GA}$ ) for an 18-d second round elongation. The mean number of shoots able to elongate per explant were all greater than one (the highest was 2.5) except for 
explants from two first-round media (Table 3). There is no significant difference $(P=0.796)$ in the mean number of shoots per explant among different first-round media, indicating the current elongation medium is suitable for explants from various culture conditions. We then cultured another $155 \mathrm{~F}$. mandshurica hypocotyls on this elongation medium. Approximate $70.97 \%$ explants survived and were able to elongate $3-4 \mathrm{~cm}$ after two to three rounds of subculture (Fig. $4 \mathrm{c}$ ), confirming the stability of this protocol.

Table 3

Elongation sub-culture of adventitious shoots

\begin{tabular}{|llll|}
\hline Shoots source & Elongation rate(\%) & Survival rate(\%) & Mean No. Seedlings per explant \\
\hline A1 & $75.00 \pm 12.50$ & $87.50 \pm 12.50$ & $1.86 \pm 0.15$ \\
\hline A2 & $100.00 \pm 0.00$ & $100.00 \pm 0.00$ & $2.00 \pm 0.20$ \\
\hline A3 & $66.67 \pm 33.35$ & $100.00 \pm 0.00$ & $0.67 \pm 0.34$ \\
\hline A4 & $100.00 \pm 0.00$ & $100.00 \pm 0.00$ & $2.50 \pm 0.25$ \\
\hline A5 & $40.00 \pm 10.00$ & $80.00 \pm 10.00$ & $0.50 \pm 0.25$ \\
\hline A6 & $71.40 \pm 14.30$ & $85.70 \pm 14.30$ & $1.83 \pm 0.17$ \\
\hline A7 & $83.33 \pm 15.28$ & $80.00 \pm 20.00$ & $2.25 \pm 0.25$ \\
\hline A8 & $54.53 \pm 9.05$ & $72.70 \pm 9.10$ & $1.00 \pm 0.25$ \\
\hline
\end{tabular}

The rootless plantlets were then transplanted in pods for rooting. Lateral roots were visible after cultured in sealed plastic bags for 10 days (Fig. 5b). The plastic bags were removed after cultured for a total of 30 days (Fig. 5c). After another $30-\mathrm{d}$ culture under $25^{\circ} \mathrm{C}$ and $40 \%$ humidity, the survival rate of the plantlets reached $72 \%$ (Fig. 5 d).

\section{Determining the concentration of kanamycin on hypocotyl activity}

To determine the appropriate concentration of kanamycin to select putative transformants, hypocotyls were horizontally inoculated to WPM supplemented with different concentrations of kanamycin (Table 4). The mortality rate increased as the concentration of kanamycin increased, reached $93.33 \%$ at the kanamycin concentration of $50 \mathrm{mg} \mathrm{L}^{-1}$, and reached $100.00 \%$ at the kanamycin concentration of $50 \mathrm{mg}$ $\mathrm{L}^{-1}$. Significant difference was observed among various kanamycin concentrations in mortality rates $(P$ $=0.001$ ). Therefore, $30 \mathrm{mg} \mathrm{L}^{-1}$ kanamycin was used as the supplement for the selection medium. 
Table 4

Effect of kanamycin concentration of Fraxinus

mandshurica hypocotyls

\begin{tabular}{|ll|}
\hline $\begin{array}{l}\text { Kanamycin } \\
(\mathrm{mg} / \mathrm{L})\end{array}$ & death rate (\%) \\
\hline 0 & $13.33 \pm 11.55$ \\
\hline 20 & $40.00 \pm 20.00$ \\
\hline 30 & $93.33 \pm 5.77$ \\
\hline 50 & $100.00 \pm 0.00$ \\
\hline 60 & $76.67 \pm 40.41$ \\
\hline
\end{tabular}

Impact of Agrobacterium infection time on hypocotyl regeneration

Infection time is an important factor that affects transformation efficiency. To determine the infection time for Agrobacterium-mediated transformation, we tested 10, 15, and 20 min using the traditional Agrobacterium infection method (Table 5). The highest germination rate $(71.62 \%)$ was observed in the period of $15 \mathrm{~min}$, with a mortality rate of $21.07 \%$. Neither the induction rate $(P=0.886)$ nor the mortality rate $(P=0.906)$ was observed to be significantly different among different infection times. However, the infection time showed a significant difference in the formation of callus $(P=0.009)$. A larger number and healthier adventitious shoot buds were formed per explant (Fig. 6) if treated for 15 min compared to those treated for 10 or $20 \mathrm{~min}$. Therefore, $15 \mathrm{~min}$ was used as the infection time in the following Agrobacterium-mediated transformation.

Table 5

Effect of infection time on hypocotyl differentiation of Fraxinus mandshurica

\begin{tabular}{|llll|}
\hline Time(min) & Shoot formation (\%) & $\begin{array}{l}\text { Callus formation } \\
(\%)\end{array}$ & $\begin{array}{l}\text { Explants mortality } \\
(\%)\end{array}$ \\
\hline 10 & $66.67 \pm 14.43$ & $33.33 \pm 8.34$ & $15.28 \pm 13.39$ \\
\hline 15 & $71.62 \pm 11.51$ & $77.30 \pm 9.20$ & $21.07 \pm 21.88$ \\
\hline 20 & $66.99 \pm 14.82$ & $59.08 \pm 15.09$ & $22.46 \pm 25.38$ \\
\hline
\end{tabular}

Agrobacterium -mediated transformation of F. mandshurica

In this study, two methods were used for Agrobacterium infection. Compared to traditional Agrobacterium infection method, hypocotyls treated by using the sonication plus vacuum-infiltration method produced more buds (72.70\%) on induction media (Table 6; Fig. 8). All transformants infected by using traditional method showed albino plantlets and finally died (Fig. 7) after cultured on selection media supplemented 
with $30 \mathrm{mg} \mathrm{L}^{-1}$ kanamycin and $500 \mathrm{mg} \mathrm{L}^{-1}$ cephalosporin for 20 days, indicating a lower transformation rate of the traditional Agrobacterium infection method in F. mandshurica. While for explants infected using the sonication plus vacuum-infiltration method, 3.80\% survived after cultured on the same selection medium for 40 days (Table 6). The histochemical staining analysis of infected and cultured hypocotyl for 3 days showed that the wound and surface of the injured hypocotyl explant were blue (Fig. 8), and the transformation rate of transient infection was $93.33 \%$. This suggested that the hypocotyls infected by sonication plus vacuum-infiltration had GUS activity and the surface tissue of hypocotyls was destroyed, which could increase the probability of infection by Agrobacterium. The kanamycin-resistant plantlets were subjected to PCR analysis. Target fragments (Fig. 9) were detected in 4 out of 112 plantlets (3.57\%), suggesting that the regeneration system from hypocotyl meets the requirements of genetic transformation of F. mandshurica.

Table 6

Traditional method and Sonication plus vacuum-infiltration assisted agrobacterium-mediated transformation

\begin{tabular}{|lllll|}
\hline & $\begin{array}{l}\text { 20d Shoot } \\
\text { formation(\%) }\end{array}$ & $\begin{array}{l}\text { 40d Shoot } \\
\text { formation(\%) }\end{array}$ & $\begin{array}{l}\text { Callus } \\
\text { formation (\%) }\end{array}$ & $\begin{array}{l}\text { Selective survival } \\
\text { rate (\%) }\end{array}$ \\
\hline Control & $88.33 \pm 6.03$ & $88.33 \pm 6.03$ & $11.76 \pm 5.89$ & $0.00 \pm 0.00$ \\
\hline Traditional method & $51.57 \pm 9.61$ & $71.62 \pm 11.51$ & $77.30 \pm 9.20$ & $0.00 \pm 0.00$ \\
\hline $\begin{array}{l}\text { Sonication plus } \\
\text { vacuum-infiltration }\end{array}$ & $64.69 \pm 15.36$ & $72.70 \pm 4.98$ & $2.74 \pm 2.54$ & $3.80 \pm 2.30$ \\
\hline & & & & \\
\hline
\end{tabular}

\section{Discussion}

TDZ is widely used in in vitro plant tissue culture to induce shoot growth[17], somatic embryogenesis[18, 19], protoplast division[20], and protocorm-like body morphogenesis [21]. Zeng et al. [22]found that the frequency of shoot organogenesis of explants cultured with TDZ (71.16\%) far surpassed those cultured without TDZ (30.42\%). We have showed in this study that the germination of the adventitious buds from hypocotyls of $F$. mandshurica was affected by TDZ concentration. The highest germination rate $(82.22 \%)$ of adventitious shoot buds from hypocotyls was obtained on the induction medium supplemented with $1.0 \mathrm{mg} \mathrm{L}^{-1} \mathrm{TDZ}$, indicating TDZ may play a key role in regulating the germination of adventitious shoot buds on F. mandshurica hypocotyls. However, on the induction medium supplemented with both TDZ and BA, the germination rate was decreased with an increase in TDZ concentration (Table 1), suggesting that TDZ alone is able to induce direct organogenesis of hypocotyls. This result is consistent with the previous reports that TDZ can substitute auxins and cytokinins[23, 24], and Murashige and Skoog (MS) medium supplemented with TDZ instead of BA increased the proportion of $F$. excelsior hypocotyl explants that produced adventitious shoots[25]. We also observed that hypocotyls produced more adventitious shoot buds if incubated in the dark, while they aged and formed calluses (inhibited the explant regeneration) under light conditions (Fig. 3). Our result is similar with those of Jain et al. [26], who 
reported that the basal segment from hypocotyl of Linum usitatissimum produced a large number of shoots in a short period with a low concentration of TDZ and dark incubation.

Reports have shown that different portions of the hypocotyls had different regenerative capacities. The hypocotyls with root and apical meristems removed exhibited the highest regenerative capacity[27]. In this study, all explants with hypocotyl could form adventitious buds(Fig. 2a), while explants which only have radicles could only form calluses(Fig. $2 \mathrm{~h}$ ). In addition, difference in germination rate was also observed between hypocotyls with and without potassium citrate pretreatment. Ajay et al. [28] revealed in Sesbania restrata that adventitious shoot formation from 12-day-old hypocotyl explants had a higher regeneration rate than 14- or 18-day-old hypocotyl explants. Hypocotyl explants of 3-5-day-old (> 80\% regeneration rate) Chinese cabbage had more potential to regenerate than 7 -day-old $(51.1 \%$ regeneration rate) explants[29]. Du et al.[27] found that with an increasing age of explants, organogenesis potential of explants was decreased in F. pennsylvanica. There was no adventitious shoot regeneration when 15-dayold hypocotyls and 7-, 10- or 15-day-old cotyledons were used as explants. It was reported that organic acids were able to enhance the embryogenesis of callus. The potassium citrate pretreatment may cause an alteration in cellular metabolism towards cell differentiation and away from cell proliferation, which promoted the regeneration of peppers [30]. In this study, explants pretreated with $6 \mathrm{~g} \mathrm{~L}^{-1}$ potassium citrate for 3-5 days showed a higher regeneration rate (86.7\%) than those explants without pretreatment. Meanwhile, the number of adventitious shoot buds per explant were greater on pretreated explants (Fig. 2g), and it further increased if explants were infected using sonication plus vacuum-infiltration during the Agrobacterium-mediated transformation (Fig. 8). This finding is different from those obtained from the regeneration of other F. mandshurica [13] or ashes [27], indicating that the regeneration rate of $F$. mandshurica hypocotyls not only depends on the starting hypocotyl explants and time of pretreatment, but also depends on the supplement used in pretreatment and other external stimulations.

In many plants, the whole plant individuals are able to regenerate from small tissues, such as leaves, stems, and roots[31]. An important aspect of organ regeneration is the reactivation of cell proliferation at wound sites, leading to the formation of callus and subsequent establishment of shoot or root apical meristems [32]. In some cases, organogenesis occurs without the formation of callus. This may be caused by genetic regulation of plant cellular reprogramming induced by wounds or plant hormones[33]. In this study, the highest germination rate (86.67\%) was achieved for explants pretreated with potassium citrate, while an even higher germination rate (88.33\%) was observed during the Agrobacterium-mediated transformation when wounds were created on explants by using the sonication and vacuum-infiltration method. This further demonstrates that wounds promoted plant regeneration, which may not necessarily induce callus formation. In addition, the requirement of light with low intensity for producing adventitious shoots suggests that plant regeneration is not only affected by wounds or plant hormones, but also by light intensities.

\section{Conclusions}


In this study, a rapid and efficient regeneration system of $F$. mandshurica was developed. The adventitious shoots able to subsequently elongate to vigorous plantlets were obtained from $F$. mandshurica hypocotyls in an affordable time. On the basis of this regeneration system, a protocol of $A$. tumefaciens-mediated transformation of hypocotyl explants was established and positive transgenic plantlets were obtained. The regeneration system, along with the transformation protocol, allowed us to produce the adventitious shoots, tissue culture plantlets, and rooted plantlets in 40, 80-100, and 160 days. Moreover, this regeneration system also established the foundation for forest development, genetic improvement, and gene function verification of $F$. mandshurica.

\section{Methods}

\section{Plant materials}

Fraxinus mandshurica seeds were collected from the elite varieties of Heilongjiang Province, China: annual seeds obtained from the families of Fraxinus mandshurica No. 70, 46, 76, 64 and 72 and excellent hybrid combinations The seeds were soaked in tap water for 24 hours, and rinsed with running tap water for $1 \mathrm{~h}$. After removal of the pericarps, the seeds were agitated in $75 \%(\mathrm{v} / \mathrm{v})$ ethanol for $30 \mathrm{~s}$, and then rinsed 3 times with sterile distilled water. The seeds were then again surface sterilized in $10 \%(\mathrm{v} / \mathrm{v})$ $\mathrm{NaClO}_{2}$ for $10-15$ min, and rinsed 5 times with sterile distilled water.

\section{Pre-culture of explants}

The turgid embryos were extracted from the sterilized seeds under aseptic conditions, and placed on either the WPM (30 g L-1 sucrose and $5.6 \mathrm{~g} \mathrm{~L}^{-1}$ agar; $\mathrm{pH}=6.0$ ) (Lloyd and McCown 1980) without any supplement or that supplemented with $6 \mathrm{~g} \mathrm{~L}^{-1}$ potassium citrate. The embryos were pre-cultured in the dark at $25 \pm 2{ }^{\circ} \mathrm{C}$ for 3 to 5 days.

\section{Induction of adventitious shoot buds}

Radicles and cotyledons were removed from embryos, and the hypocotyls were horizontally inoculated on the different combinations of PGRs media supplemented with WPM to induce adventitious shoot bud formation. The hypocotyls were incubated at $25 \pm 2{ }^{\circ} \mathrm{C}$ for an initial 2 weeks in the dark, followed by cultured under a low light with intensity of $10 \mu \mathrm{mol} \mathrm{m} \mathrm{m}^{-1}$ for another 20 days. The induction medium is:

WY1区0.4mg $\cdot \mathrm{L}^{-1} \mathrm{TDZ}+\mathrm{WPM}+30 \mathrm{~g} \cdot \mathrm{L}^{-1}$ sucrose $+5.6 \mathrm{~g} \cdot \mathrm{L}^{-1}$ agar

WY2ه0.6mg $\cdot \mathrm{L}^{-1} \mathrm{TDZ}+\mathrm{WPM}+30 \mathrm{~g} \cdot \mathrm{L}^{-1}$ sucrose $+5.6 \mathrm{~g} \cdot \mathrm{L}^{-1}$ agar

WY3®0.8mg $\cdot \mathrm{L}^{-1} \mathrm{TDZ}+\mathrm{WPM}+30 \mathrm{~g} \cdot \mathrm{L}^{-1}$ sucrose $+5.6 \mathrm{~g} \cdot \mathrm{L}^{-1}$ agar

WY4ه1.0mg $\cdot \mathrm{L}^{-1} \mathrm{TDZ}+\mathrm{WPM}+30 \mathrm{~g} \cdot \mathrm{L}^{-1}$ sucrose $+5.6 \mathrm{~g} \cdot \mathrm{L}^{-1}$ agar

WY $5 ₫ 0.08 \mathrm{mg} \cdot \mathrm{L}^{-1} \mathrm{TDZ}+1.0 \mathrm{mg} \cdot \mathrm{L}^{-1} \mathrm{BA}+\mathrm{WPM}+30 \mathrm{~g} \cdot \mathrm{L}^{-1}$ sucrose $+5.6 \mathrm{~g} \cdot \mathrm{L}^{-1}$ agar 
WY6 $₫ 0.8 \mathrm{mg} \cdot \mathrm{L}^{-1} \mathrm{TDZ}+1.0 \mathrm{mg} \cdot \mathrm{L}^{-1} \mathrm{BA}+\mathrm{WPM}+30 \mathrm{~g} \cdot \mathrm{L}^{-1}$ sucrose $+5.6 \mathrm{~g} \cdot \mathrm{L}^{-1}$ agar

\section{Elongation of adventitious shoots}

All explants initiating shoot buds were transferred to different elongation media. To test the effect of different plant growth regulator combinations, WPM medium was supplemented with different combinations of GA3, TDZ, BA, and NAA. Cultures were incubated under a 16-h photoperiod with a light intensity of $80 \mu \mathrm{mol} \mathrm{m} \mathrm{m}^{-2} \mathrm{~s}^{-1}$ at $25^{\circ} \mathrm{C}$ for 30 days. The elongation and survival rates of shoot buds, and the shoot number on each explant were recorded. A suitable elongation medium was selected for secondary elongation. The elongation medium is:

A1 $₫ 0.025 \mathrm{mg} \cdot \mathrm{L}^{-1} \mathrm{TDZ}+1.0 \mathrm{mg} \cdot \mathrm{L}^{-1} \mathrm{GA} 3+\mathrm{WPM}+30 \mathrm{~g} \cdot \mathrm{L}^{-1}$ sucrose $+5.6 \mathrm{~g} \cdot \mathrm{L}^{-1}$ agar

A2ख0.05mg $\cdot \mathrm{L}^{-1} \mathrm{TDZ}+1.0 \mathrm{mg} \cdot \mathrm{L}^{-1} \mathrm{GA} 3+\mathrm{WPM}+30 \mathrm{~g} \cdot \mathrm{L}^{-1}$ sucrose $+5.6 \mathrm{~g} \cdot \mathrm{L}^{-1}$ agar

A3®0.05mg $\cdot \mathrm{L}^{-1} \mathrm{TDZ}+2.0 \mathrm{mg} \cdot \mathrm{L}^{-1} \mathrm{GA} 3+0.6 \mathrm{mg} \cdot \mathrm{L}^{-1} \mathrm{BA}+\mathrm{WPM}+30 \mathrm{~g} \cdot \mathrm{L}^{-1}$ sucrose $+5.6 \mathrm{~g} \cdot \mathrm{L}^{-1}$ agar

$\mathrm{A} 4 \llbracket 0.05 \mathrm{mg} \cdot \mathrm{L}^{-1} \mathrm{TDZ}+2.0 \mathrm{mg} \cdot \mathrm{L}^{-1} \mathrm{GA} 3+\mathrm{WPM}+30 \mathrm{~g} \cdot \mathrm{L}^{-1}$ sucrose $+5.6 \mathrm{~g} \cdot \mathrm{L}^{-1}$ agar

A5『0.025 mg $\cdot \mathrm{L}^{-1} \mathrm{TDZ}+0.6 \mathrm{mg} \cdot \mathrm{L}^{-1} \mathrm{BA}+\mathrm{WPM}+30 \mathrm{~g} \cdot \mathrm{L}^{-1}$ sucrose $+5.6 \mathrm{~g} \cdot \mathrm{L}^{-1}$ agar

A6『0.025 $\mathrm{mg} \cdot \mathrm{L}^{-1} \mathrm{TDZ}+1.5 \mathrm{mg} \cdot \mathrm{L}^{-1} \mathrm{BA}+\mathrm{WPM}+30 \mathrm{~g} \cdot \mathrm{L}^{-1}$ sucrose $+5.6 \mathrm{~g} \cdot \mathrm{L}^{-1}$ agar

A7ه1.0mg $\cdot \mathrm{L}^{-1} \mathrm{TDZ}+5.0 \mathrm{mg} \cdot \mathrm{L}^{-1} \mathrm{BA}+\mathrm{WPM}+30 \mathrm{~g} \cdot \mathrm{L}^{-1}$ sucrose $+5.6 \mathrm{~g} \cdot \mathrm{L}^{-1}$ agar

A8ه0.6mg $\cdot \mathrm{L}^{-1} \mathrm{TDZ}+1.0 \mathrm{mg} \cdot \mathrm{L}^{-1} \mathrm{NAA}+\mathrm{WPM}+30 \mathrm{~g} \cdot \mathrm{L}^{-1}$ sucrose $+5.6 \mathrm{~g} \cdot \mathrm{L}^{-1}$ agar

\section{Rooting and acclimatization of plantlets}

The rootless plantlets were transplanted into $\varangle 9 \times 13 \mathrm{~cm} \otimes$ plastic pots containing a substrate with autoclaved peat soil and vermiculite (3:1, v/v), and the WPM medium supplemented with $3 \mathrm{mg} \mathrm{L}^{-1}$ indole3-butyric acid (IBA) was added. The pods were placed in sealed $\nabla 16 \times 24 \mathrm{~cm} \rrbracket$ plastic bags to provide a high relative humidity and grown at $25^{\circ} \mathrm{C}$ and $80 \mu \mathrm{mol} \mathrm{m}^{-2} \mathrm{~s}^{-1}$ photoperiod for 30 days. The plastic bags were then progressively opened and plantlets were cultured under $25^{\circ} \mathrm{C}$ and $40 \%$ humidity for another 30 days.

\section{Agrobacterium tumefaciens strain and plasmid}

The FmLWD1 gene (gifted by Dr. Yang Cao from our laboratory) was inserted into the Proke2 plasmid vector (gifted by Dr. Yang Cao from our laboratory), which carries $\beta$-glucuronidase (GUS) fusion gene under the control of the cauliflower mosaic virus (CaMV) 35S promoter (Figure 10) by using KpnI restriction enzyme (Thermo Fisher Scientific) digestion. The vector was then introduced into Agrobacterium tumefaciens strain LBA4404 (Freeze storage at $-80^{\circ} \mathrm{C}$ in our laboratory) and used for plant transformation. 


\section{Effect of kanamycin on hypocotyl regeneration}

To determine the optimal concentration of kanamycin for screening out positive plantlets, 15-day-old hypocotyls were inoculated on WPM media containing kanamycin in a concentration gradient of 0,20 , $30,40,50$, or $60 \mathrm{mg} \mathrm{L}^{-1}$. Kanamycin was dissolved in sterile distilled water, filter-sterilized $(0.22 \mu \mathrm{m})$, and added to the medium after autoclaving. The medium without adding kanamycin was set as the control group. For each treatment, 30 hypocotyls were inoculated, and results were recorded after 40 days of being cultured.

\section{Effect of Agrobacterium infection time on hypocotyl regeneration}

A. tumefaciens was grown in $50 \mathrm{mLYEB}$ liquid medium supplemented with $50 \mathrm{mg} \mathrm{L}^{-1}$ rifampicin and 50 $\mathrm{mg} \mathrm{L}^{-1}$ kanamycin. The culture was incubated overnight at $28^{\circ} \mathrm{C}$ with shaking $(250 \mathrm{rpm})$. When the culture was at density of $0.6 \mathrm{OD}_{600}$, bacterial cells were resuspended in the inoculation medium.

Hypocotyl segments were immersed in $50 \mathrm{~mL}$ Agrobacterium suspension for 10, 15, or $20 \mathrm{~min}$. Explants were blotted on sterile filter paper to remove excess bacterial solution before transfer to co-cultivation media (WY4) and incubated in the dark for 3 days. After 3 days co-cultivation, hypocotyl segments were washed $2 \mathrm{~min}$ times with sterile, distilled water to remove excess bacteria, blotted on sterile filter paper, transferred to the WY4 medium supplemented with $500 \mathrm{mg} \mathrm{L}^{-1}$ cephalosporin, and cultured for 3 days. The germination rate of adventitious shoot buds and the mortality rate of explants were recorded after 40 days of culture following the adventitious shoot induction protocol described previously.

\section{Agrobacterium-mediated transformation}

Following the optimized infection time (15 min), two methods were used for Agrobacterium-mediated transformation. With the traditional method, hypocotyl segments were immersed in $50 \mathrm{~mL}$ Agrobacterium suspension for $15 \mathrm{~min}$. While with the sonication plus vacuum-infiltration method [34], the explants were first sonicated for $90 \mathrm{~s}$ and then vacuum-infiltrated under the pressure of $0.8 \mathrm{Mpa}$ for $15 \mathrm{~min}$. Explants were blotted on sterile filter paper to remove excess bacterial solution before being transferred to cocultivation media and incubated in the dark for 3 days. After 3 days of co-cultivation, the explants were washed with sterile distilled water, transferred to induction medium. After being cultured for 20 days, explants with adventitious shoots initiated were transferred to selection medium $30 \mathrm{mg} \mathrm{L}^{-1}$ kanamycin and $500 \mathrm{mg} \mathrm{L}^{-1}$ cephalosporin.

\section{Histochemical GUS assay}

Hypocotyl explants were first sonicated for $90 \mathrm{~s}$ in liquid induction medium and then vacuum-infiltrated under the pressure of $0.8 \mathrm{Mpa}$ for $15 \mathrm{~min}$ in $0.6 \mathrm{OD}_{600}$ Agrobacterium resuspension. After being shaken for $16 \mathrm{~h}$, the explants were inoculated into solid induction medium for 2 days. Take out and immersed in GUS buffer solution $\left(25 \mathrm{ml} 0.2 \mathrm{M} \mathrm{Na}_{3} \mathrm{PO}_{4}, 6.2 \mathrm{ml} 0.2 \mathrm{M} \mathrm{Na}_{2} \mathrm{HPO}_{4}\right.$ and $28 \mathrm{ml} 0.2 \mathrm{M} \mathrm{NaH}_{2} \mathrm{PO}_{4}$ were mixed to form $0.2 \mathrm{M}$ phosphate buffer ( $\mathrm{pH} 7.0$ ). The $25 \mathrm{ml}$ phosphate buffer was mixed with $0.25 \mathrm{ml} 0.1 \mathrm{M} \mathrm{K}_{3}[\mathrm{Fe}$ 


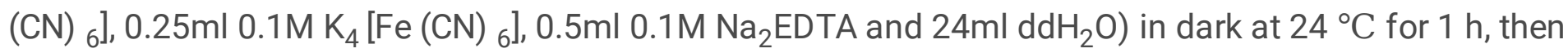
GUS buffer solution was sucked out with a pipette.

\section{PCR analysis}

Genomic DNA was isolated from leaves of six inde-pendent putative transgenic lines and from one control (non-transformed) plant following either the protocol of the Plant DNA Lsolation Reagent (TaKaRa Da Lian, China).PCR was performed primer set (forward primer MCS1-F 5' CACTATCCTTCGCAAGACCCT 3' and reverse prime MCS1-R 5' CCAGACTGAATGCCCACAGG 3') was designed to amplify a 1353bp PCR product containing CaMV 35S promoter, GUS gene, and 968 bp full length of $F m L W D 1$ gene. PCR analysis was carried out in a reaction volume of $25 \mu \mathrm{l}$ containing $12.5 \mu \mathrm{l}$ of $10 \times$ T5 buffer (TaKaRa Da Lian, China ), $1 \mu$ l of $10 \mu \mathrm{mol} \mathrm{L}-1$ MCS1-F, $1 \mu \mathrm{l}$ of $10 \mu \mathrm{mol} \mathrm{L}^{-1}$ MCS1-R, and $1 \mu \mathrm{l}$ of inde-pendent putative transgenic lines or non-transformed DNA template. DNA from non-transformed plantlets and the recombinant plasmid (pROK2: FmLWD1-GUS) were used as negative and positive controls, respectively. The PCR reaction included a pre-denaturation step of $98^{\circ} \mathrm{C}$ for $3 \mathrm{~min}$, followed by 30 cycles of denaturation of $98^{\circ} \mathrm{C}$ for $10 \mathrm{~s}$, annealing of $55^{\circ} \mathrm{C}$ for $10 \mathrm{~s}$, and extension of $72^{\circ} \mathrm{C}$ for $30 \mathrm{~s}$, and a final cycle at $72{ }^{\circ} \mathrm{C}$ for 4 min. Products from PCR amplification was electrophoresis on $1.0 \%$ agarose gel.

\section{Statistical analysis}

Data statistics use SPSS 17.0 software analysis.

\section{Abbreviations}

TDZ

Thidiazuron

GA3

Gibberellic Acid

$\mathrm{BA}$

6-Benzylaminopurine

NAA

a-Naphthalene acetic acid

IBA

Indole-butyric acid

WPM

Woody Plant Medium

\section{Declarations}

Ethics approval and consent to participate

Not applicable 


\section{Consent for publication}

Not applicable.

\section{Availability of data and materials}

The datasets used and/or analysed during the current study are availablefrom the corresponding author on reasonable request

\section{Competing interests}

The authors declare no competing interests.

\section{Funding}

This study was co-funded by Heilongjiang Provincial R\&D Project on Provincial Applied Technology (GA19B201) and Open Projects of the State Key Laboratory of Tree Genetics and Breeding. The funders had no role in the study design, analysis, or preparation of the manuscript.

\section{Authors' contributions}

LL did the genetic transformation, CY constructed the vectors, ZYG designed the experiment, QFH designed the experiment, analyzed the data and wrote the manuscript. All authors have read and approved the manuscript.

\section{Acknowledgements}

We acknowledged Dr. Jing Tianzhong (Northeast Forest University) for help on data analysis.

\section{Author details}

1 Key Laboratory of Saline-alkali Vegetation Ecology Restoration, Ministry of Education (Northeast Forestry University), Harbin 150040, China.

2 College of Life Science, Northeast Forestry University, Harbin 150040, China.

Correspondence区 Feng Hui Qi 『Email『qifenghui2001@126.com;

Ya Guang Zhan囚Email『yaguangzhan@126.com

\section{References}

1. Zeng F-S, Zhou S, Zhan Y-G, Dong J. Drought resistance and DNA methylation of interspecific hybrids between Fraxinus mandshurica and Fraxinus americana. Trees. 2014;28:1679-92. 
2. Hu L-J, Uchiyama K, Shen H-L, Ide Y. Multiple-scaled spatial genetic structures of Fraxinus mandshurica over a riparian-mountain landscape in Northeast China. Conserv Genet. 2010;11:7787.

3. Zhu Z, Qi F, Yan C, Zhan Y. Sexually different morphological, physiological and molecular responses of Fraxinus mandshurica flowers to floral development and chilling stress. Plant Physiology Biochemistry. 2016;99:97-107.

4. Li L. Advances in genetics and breeding of Fraxinus mandshuric in China. Liaoning For Sci Tec. 2014:52-4.

5. Wang J, Wu L, Zhao X, Fan J, Zhang C, Gadow Kv. Influence of ground flora on Fraxinus mandshurica seedling growth on abandoned land and beneath forest canopy. Eur J For Res. 2013;132:313-24.

6. Liu W, Fan X, Wang J, Zhang C, Lu W, Gadow K. Spectral reflectance response of Fraxinus mandshurica leaves to above-and belowground competition. J Remote Sens. 2012;33:5072-86.

7. Sun X, Wang W, Razaq M, Sun H. Effects of stand density on soil organic carbon storage in the top and deep soil layers of Fraxinus mandshurica plantations. Austrian Journal of Forest Science. 2019:27-44.

8. He L, Zeng F, He Z, Li Y, Li S, Zhan Y. Interspecific hybridizations of Fraxinus L. ( F. mandshurica $\times$ F. americana and F. mandshurica $\times$ F. velutina) and heterosis analysis and selection of $\mathrm{F} 1$ progenies. Can J For Res. 2019; 49:1265-76.

9. Stener L-G. Genetic evaluation of damage caused by ash dieback with emphasis on selection stability over time. For Ecol Manag. 2018;409:584-92.

10. Chen SQ. Induction of embryogenic callus and suspension culture of tissue culture seedlings of Fraxinus mandshurica Rupr. Harbin: Northeast Forestry University; 2019.

11. Sun GJ. Maturation and germination promotion for somatic embryos of Fraxinus mandshurica Rupr. Harbin: Northeast Forestry University; 2009.

12. Zhang LJ, Zhao LM, Lu XJ, Shen HL, University SA. Callus Induction and Somatic Embryogenesis from Zygotic Cotyledons and Hypocotyls of Fraxinus mandshurica Rupr. Mol Plant Breed. 2015;13:1645-52.

13. Yang L, Bian L, Shen $\mathrm{H}-\mathrm{I}$, Li Y-h. Somatic embryogenesis and plantlet regeneration from mature zygotic embryos of Manchurian ash (Fraxinus mandshurica Rupr.). Plant Cell, Tissue and Organ Culture (PCTOC). 2013; 115:115-25.

14. Zhang LJ, Zhang LW, Feng DD. In Vitro Culture of Axillary bud Sprouting of Fraxinus mandshurica. Bull Bot Res. 2007;27:319-24.

15. Lee JH, Pijut PM. Adventitious shoot regeneration from in vitro leaf explants of Fraxinus nigra. Plant Cell, Tissue and Organ Culture (PCTOC). 2017; 130:335 - 43.

16. Wu JF, Wang Y, Wu SH. Two New Clock Proteins, LWD1 and LWD2, Regulate Arabidopsis Photoperiodic Flowering. Plant Physiol. 2008;148:948-59. 
17. Murthy BNS, Murch SJ, Saxena PK. Thidiazuron. A potent regulator ofin vitro plant morphogenesis. In Vit Cell Dev Bi Plant. 1998;34:267.

18. Li X, Krasnyanski SF, Korban SS. Somatic embryogenesis, secondary somatic embryogenesis, and shoot organogenesis in Rosa. J Plant Physiol. 2002;159:313-9.

19. Feyissa T, Welander M, Negash L. In vitro regeneration of Hagenia abyssinica (Bruce) J.F. Gmel. (Rosaceae) from leaf explants. Plant Cell Rep. 2005;24:392-400.

20. Kim SW, Oh SC, In DS, Liu JR. Plant regeneration of rose (Rosa hybridia) from embryogenic cellderived protoplasts. Plant Cell Tissue Organ Cult. 2003;73:15-9.

21. Kou Y, Yuan C, Zhao Q, Liu G, Nie J, Ma Z, Cheng C, Teixeira da Silva JA, Zhao L. Thidiazuron Triggers Morphogenesis in Rosa canina L. Protocorm-Like Bodies by Changing Incipient Cell Fate. Front Plant Sci. 2016; 7.

22. Zeng $Q$, Han Z, Kang X. Adventitious shoot regeneration from leaf, petiole and root explants in triploid (Populus alba $\times$ P. glandulosa) $\times$ P. tomentosa. Plant Cell Tissue and Organ Culture 2019:121-30.

23. Casanova Eva, Valdés AE, Fernández B, Moysset L, Trillas MI. Levels and immunolocalization of endogenous cytokinins in thidiazuron-induced shoot organogenesis in carnation. J Plant Physiol. 2004;161:95-104.

24. Thomas JC, Katterman FR. Cytokinin activity induced by thidiazuron. Plant Physiol. 1986;81:681-3.

25. Tabrett AM, Hammatt N. Regeneration of shoots from embryo hypocotyls of common ash (Fraxinus excelsior). Plant Cell Rep. 1992;11:514-8.

26. Jain P, Rashid A. Stimulation of Shoot Regeneration on Linum Hypocotyl Segments by Thidiazuron and Its Response to Light and Calcium. Biol Plant. 2001;44:611-3.

27. Du N, Pijut PM. Regeneration of plants from Fraxinus pennsy/vanica hypocotyls and cotyledons. Sci Hortic. 2008;118:74-9.

28. Kumar Jha A, Prakash S, Jain N, Nanda K, Gupta SC. Production of adventitious shoots and plantlets from the hypocotyl explants of Sesbania rostrata (Bremek \& obrem). Vit Cell Dev Bi Plant. 2002;38:430-4.

29. Zhu LH, Zhang CH, Sheng XG, Zhu YL. Studies on High Efficient System for in vitro Shoot Regeneration from Hypocotyls of Chinese Cabbage. Plant Sci J. 2005;23:427-31.

30. Buyukalaca S, Mavituna F. Somatic embryogenesis and plant regeneration of pepper in liquid media. Plant Cell Tissue Organ Cult. 1996;46:227-35.

31. Ikeuchi M, Ogawa Y, Iwase A, Sugimoto K. Plant regeneration: Cellular origins and molecular mechanisms. Dev. 2016;143:1442-51.

32. Ikeuchi M, Sugimoto K, Iwase A. Plant Callus: Mechanisms of Induction and Repression. Plant Cell. 2013;25:3159-73.

33. Ikeuchi M, Shibata M, Rymen B, Iwase A, Bågman A-M, Watt L, Coleman D, Favero DS, Takahashi T, Ahnert SE, et al. A Gene Regulatory Network for Cellular Reprogramming in Plant Regeneration. Plant 
Cell Physiol. 2018;59:770-82.

34. Du N, Pijut PM. Agrobacterium-mediated transformation of Fraxinus pennsylvanica hypocotyls and plant regeneration. Plant Cell Rep. 2009;28:915-23.

\section{Figures}

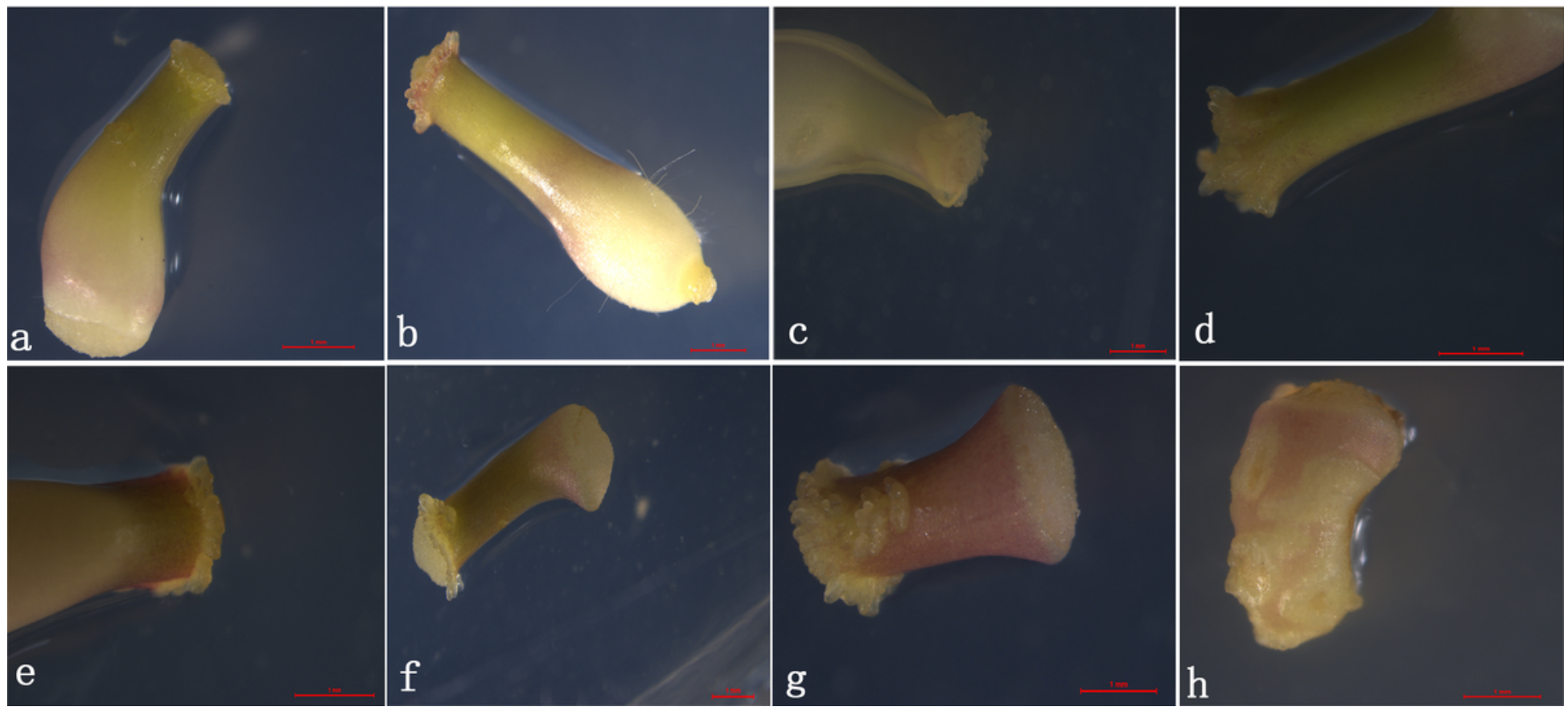

\section{Figure 1}

Hypocotyl after dark induction for $5 \mathrm{~d}$. a-f Growth situation in induction medium, respectively (bar $1 \mathrm{~mm}$ ). $\mathrm{g}$ Growth situation in contain 1.0mg $\cdot \mathrm{L}-1 \mathrm{TDZ}$ medium after potassium citrate pretreatment (bar $1 \mathrm{~mm}) . \mathrm{h}$ Growth situation of explants with only the radicle (bar $1 \mathrm{~mm}$ )

a
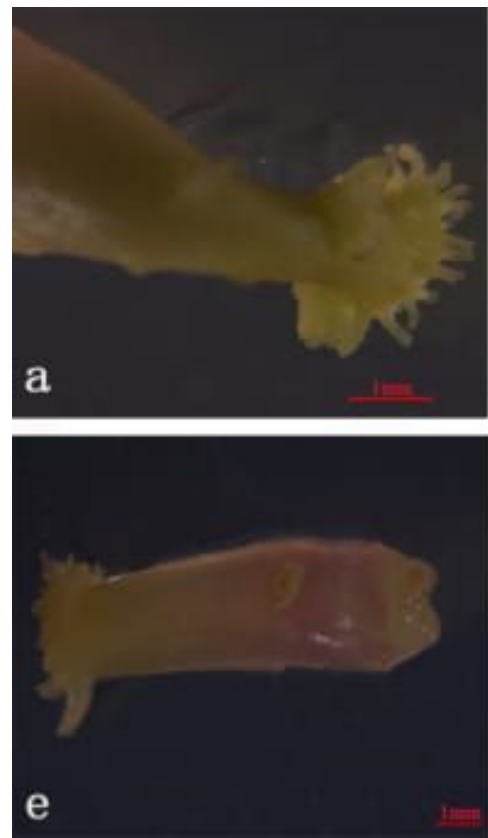
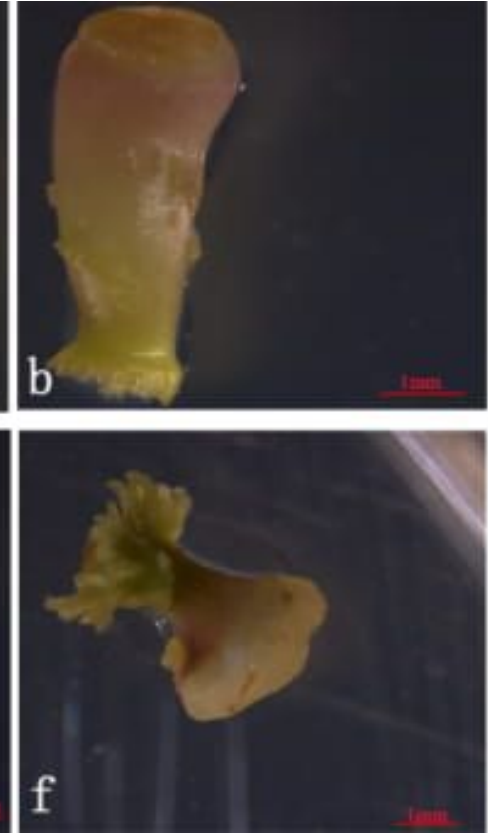

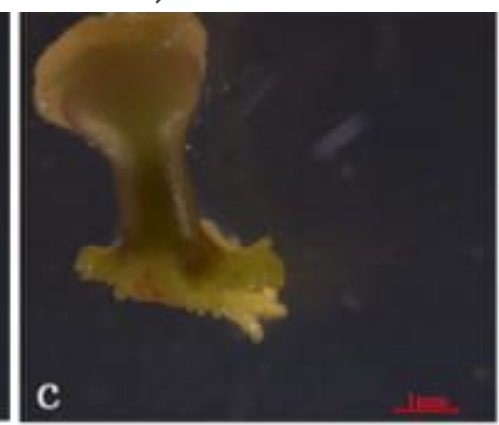

d
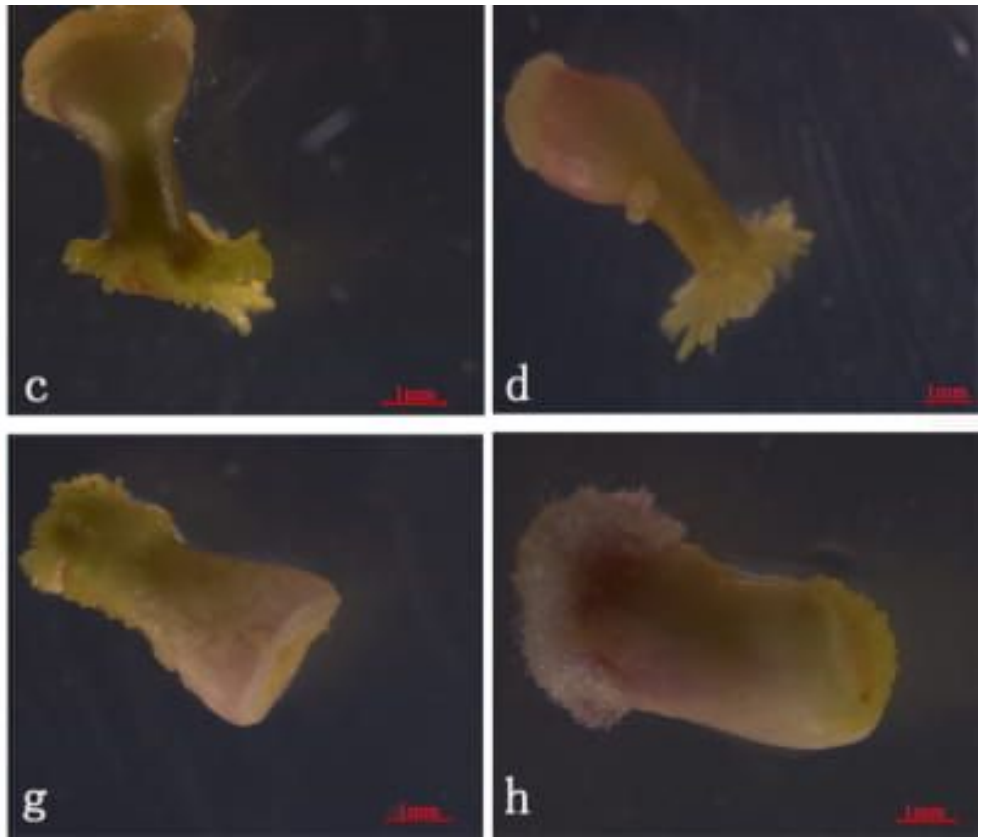


\section{Figure 2}

Hypocotyl after induction for $11 \mathrm{~d}$. a-f Growth situation in induction medium, respectively(bar $1 \mathrm{~mm}) . \mathrm{g}$ Growth situation in contain 1.0mg.L-1 TDZ medium after potassium citrate pretreatment (bar $1 \mathrm{~mm}) . \mathrm{h}$ Explants with radicles have a white, loose callus(bar $1 \mathrm{~mm}$ )
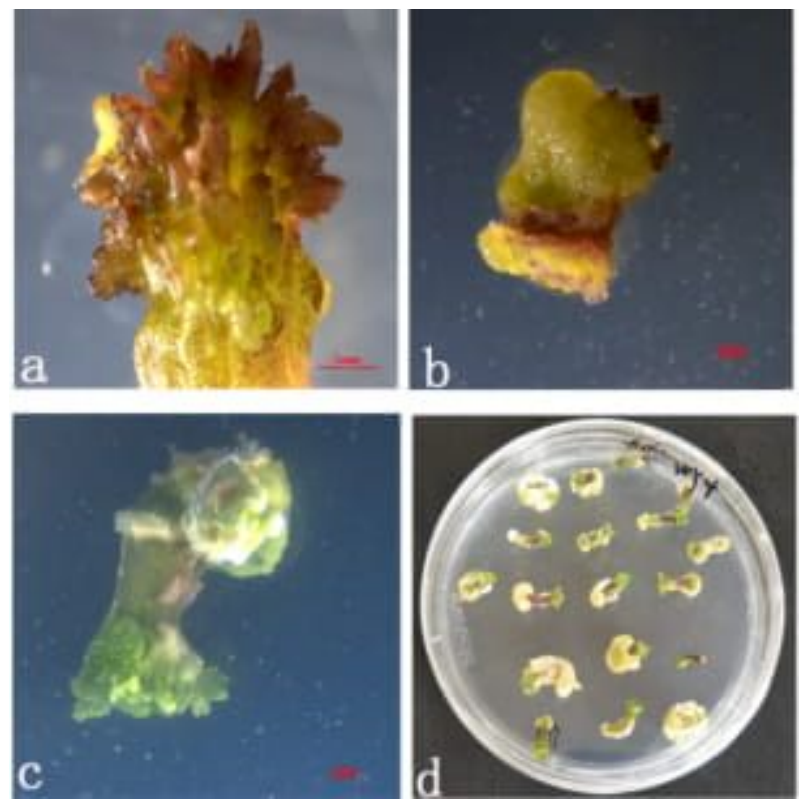

\section{Figure 3}

Adventitious shoots formation. a Hypocotyl turns red in light culture (bar $1 \mathrm{~mm}$ ). b Callus formation(bar 1 $\mathrm{mm}$ ). c Shoot points of hypocotyl turn green and adventitious shoots formation preliminarily(bar $1 \mathrm{~mm}$ ). d Adventitious shoots and callus 

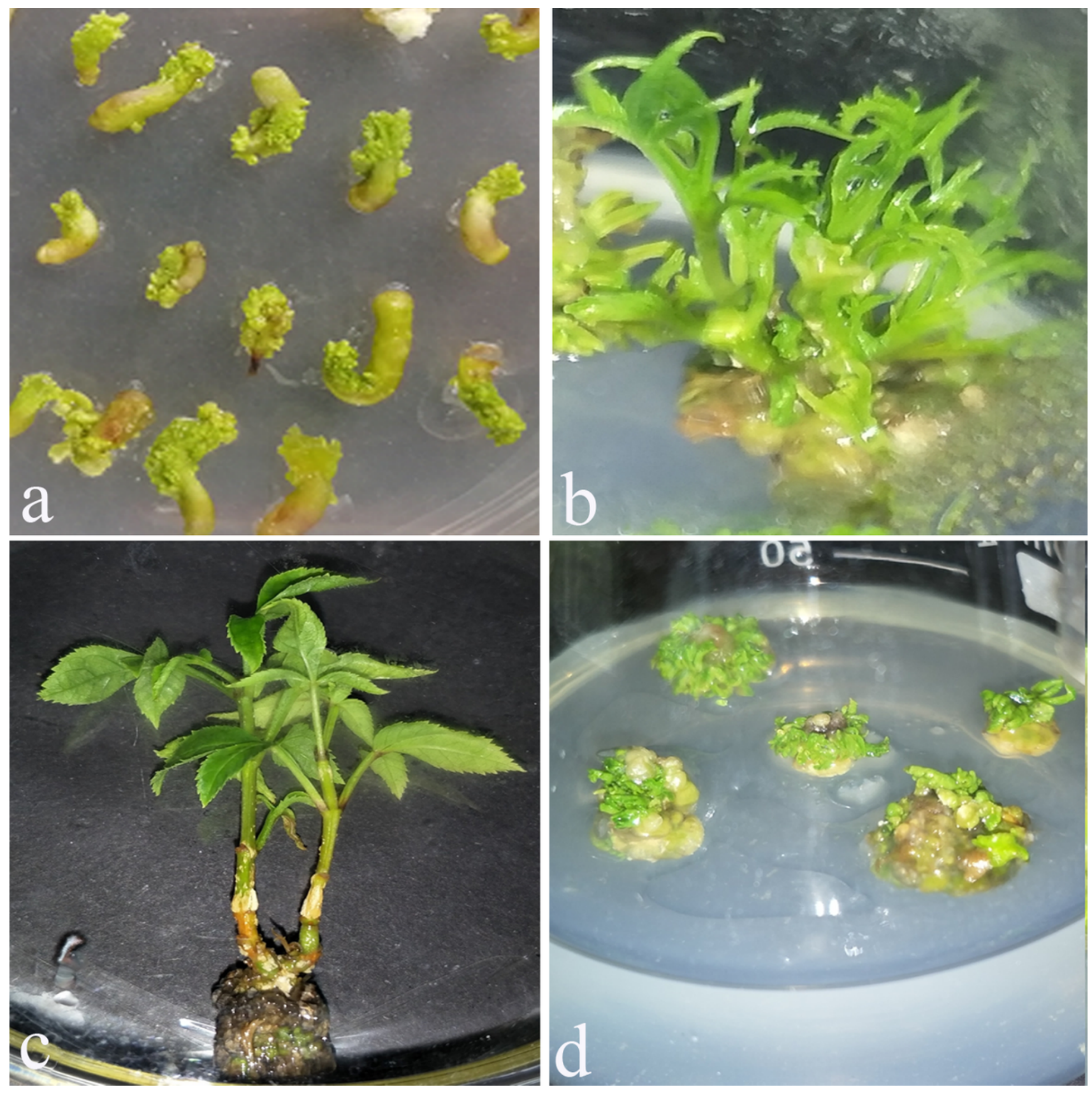

Figure 4

Elongating of Adventitious shoots. a Adventitious shoots of Fraxinus mandshurica under low light condition (see Fig. S1 in Additional file 1 for the original image). b Adventitious shoots elongation in medium supplemented with $0.025 \mathrm{mg} \cdot \mathrm{L}-1$ TDZ and $1.0 \mathrm{mg} \cdot \mathrm{L}-1 \mathrm{GA} 3$ (see Fig. S2 in Additional file 1 for the original image). c Fraxinus mandshurica regenerated seedlings after 2-3 elongated subculture. $d$ Adventitious shoots fail to elongate 

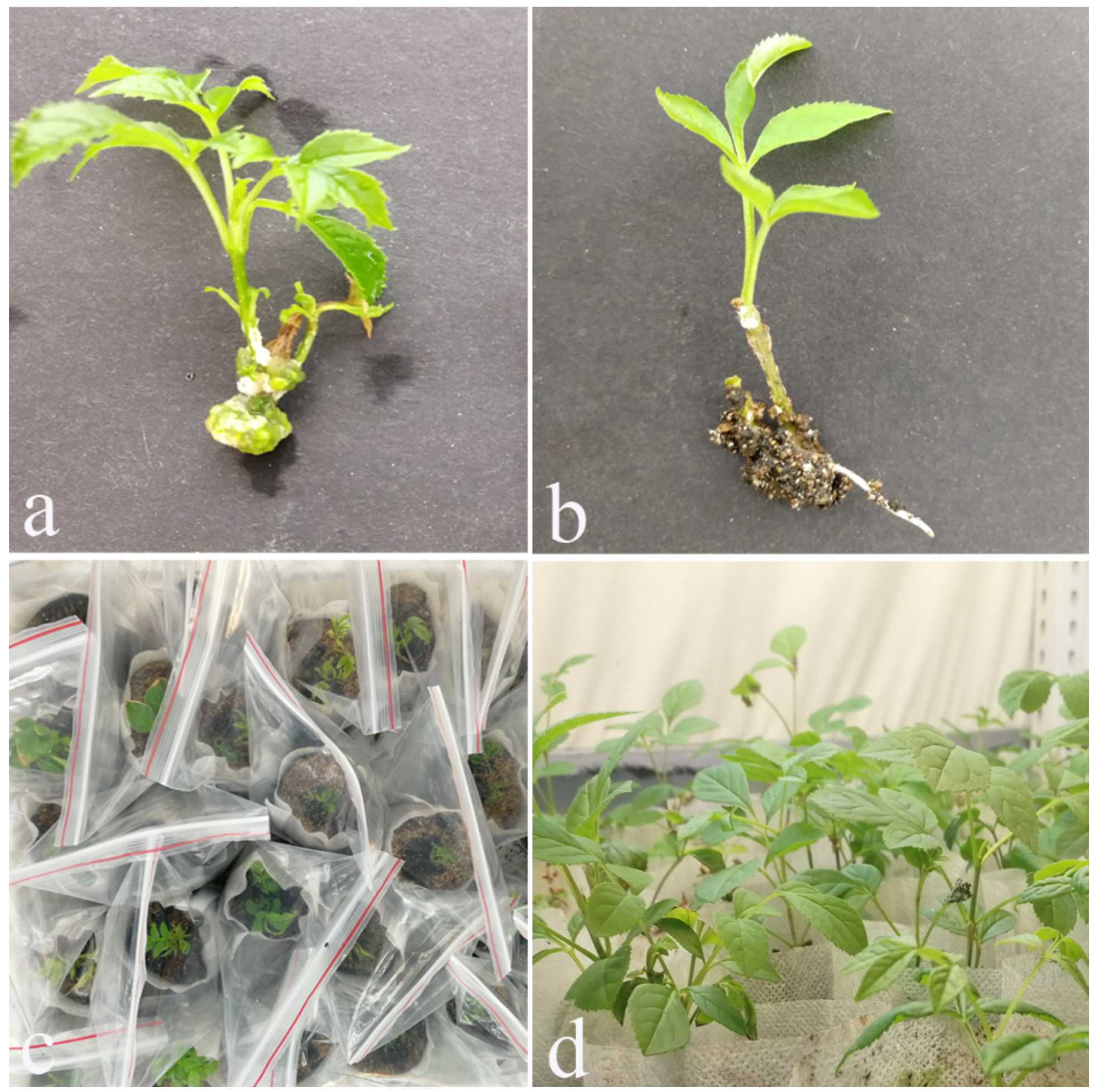

\section{Figure 5}

Transplanting and domestication of Fraxinus mandshurica regenerated seedlings. a Healthily-growing rootless regenerated seedling (see Fig. S3 in Additional file 1 for the original image). b in vitro root production. c Transplanted growth of a plant (see Fig. S4 in Additional file 1 for the original image). d Acclimatizatio of Fraxinus mandshurica plants rooted in the culture room (see Fig. S5 in Additional file 1 for the original image) 

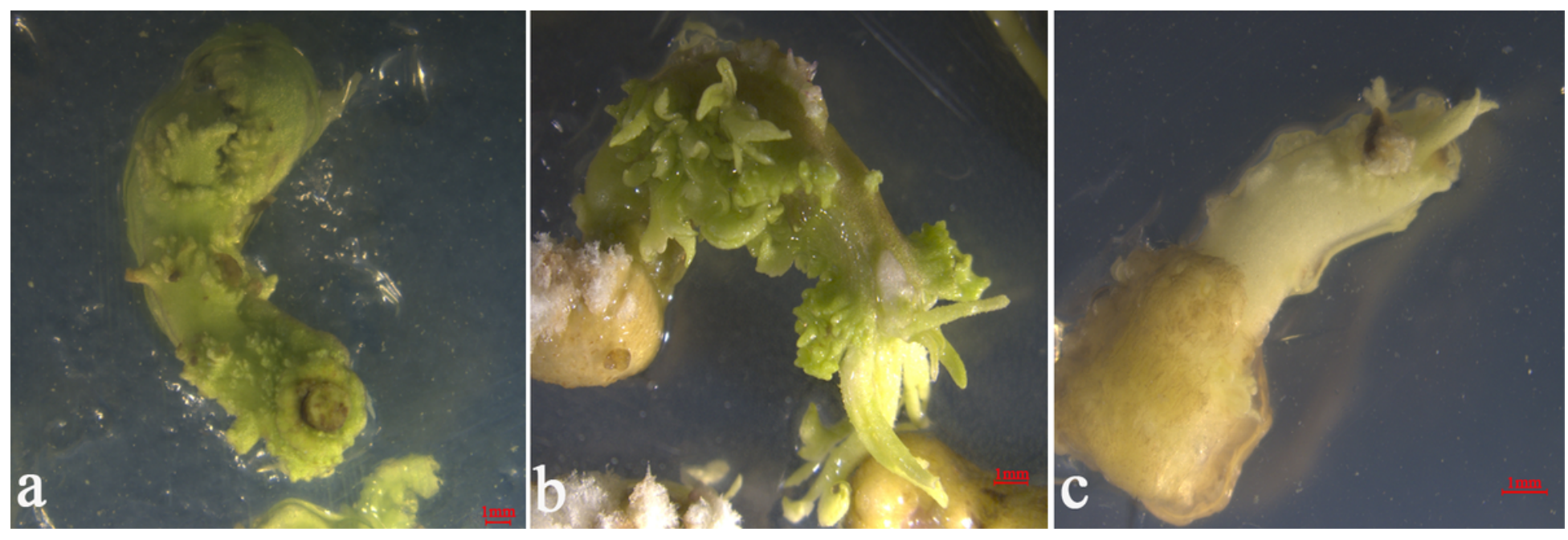

Figure 6

Effect of Agrobacterium infection time on adventitious shoots regeneration induced by hypocotyls of Fraxinus mandshurica. a The infection of $10 \mathrm{~min}$ (bar $1 \mathrm{~mm}$ ). b The infection of $15 \mathrm{~min}$ (bar $1 \mathrm{~mm}$ ). c The infection of $20 \mathrm{~min}$ (bar $1 \mathrm{~mm}$ ) 


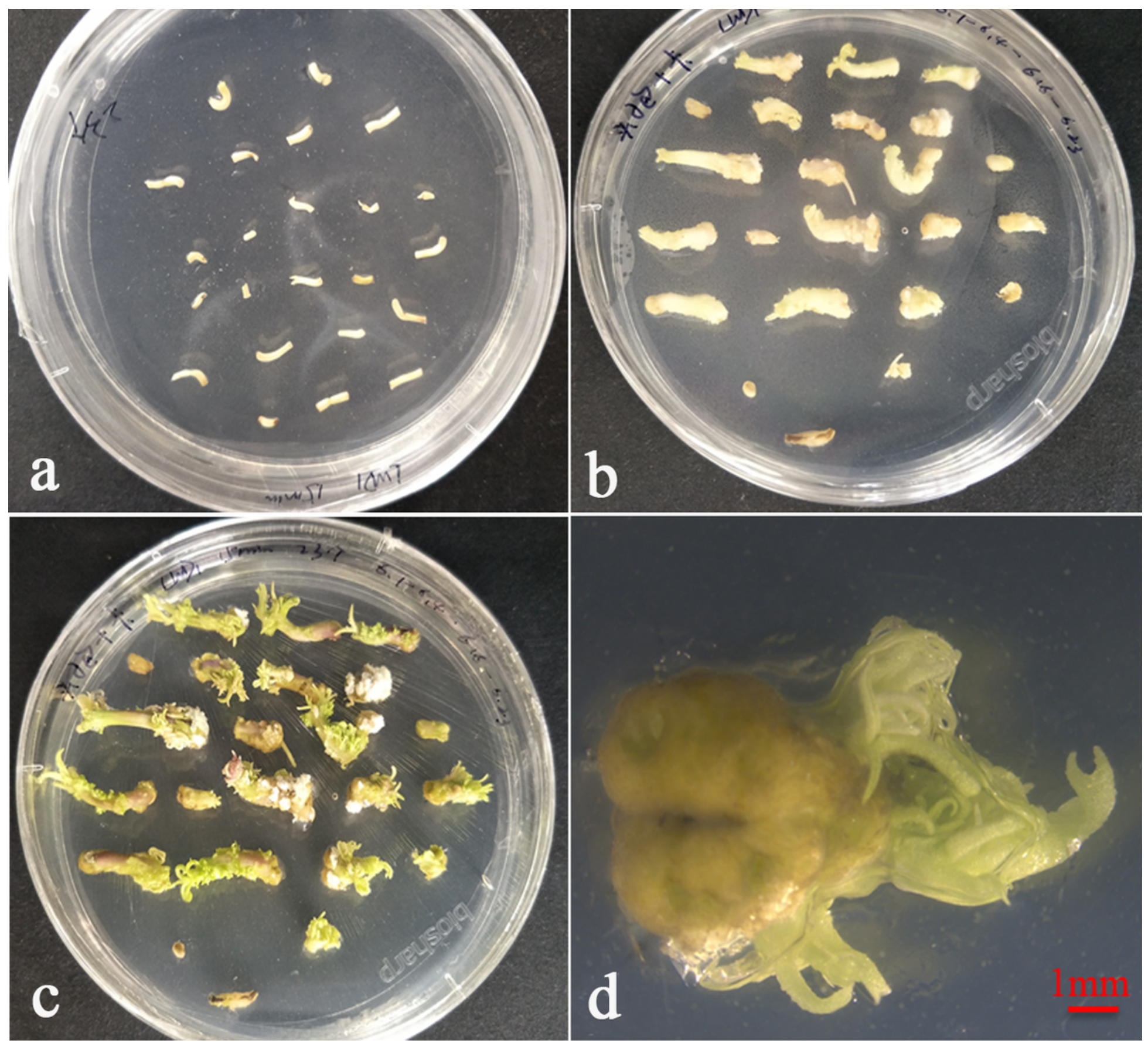

Figure 7

Traditional agrobacterium transformation. a Infection of Fraxinus mandshurica hypocotyl by agrobacterium. b After dark culture and low light induction, transferred to selective medium. c Selective cultivation for 20 days under light conditions. d Albino adventitious shoots (bar $1 \mathrm{~mm}$ ) 


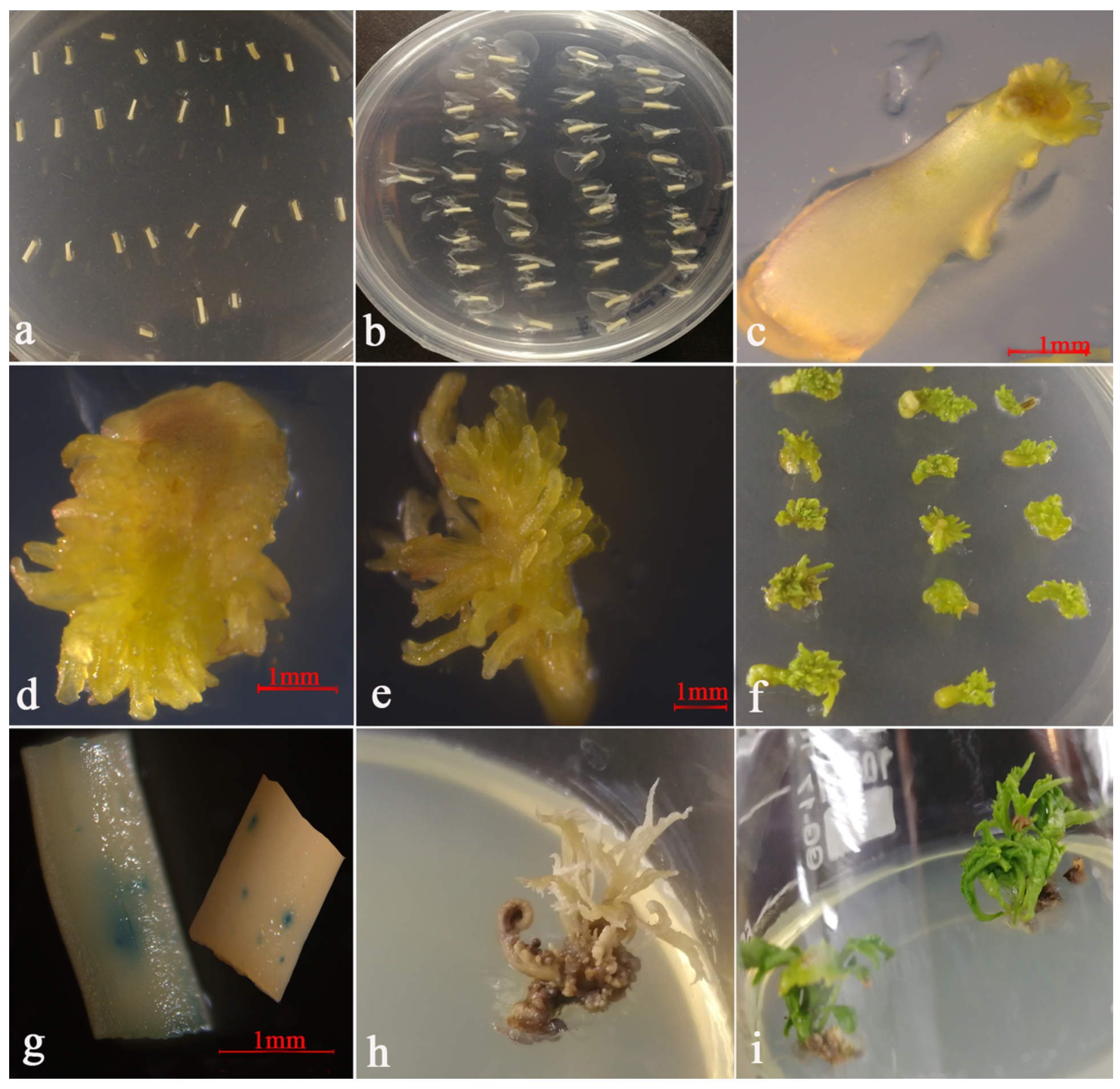

Figure 8

Sonication with vacuum-infiltration assisted agrobacterium-mediated transformation and transient GUS expression assay. a Infecting hypocotyl 1d. b Co-cultivation for 3 days. c Without sonication with vacuum-infiltration treatment of non-transformed material induced for 12 days (bar $1 \mathrm{~mm}$ ). $\mathrm{d}$ Sonication with vacuum-infiltration treatment of non-transformed material induced for 12 days(bar $1 \mathrm{~mm}$ ). e Sonication with vacuum-infiltration assisted agrobacterium-mediated transformation to induce hypocotyl for $12 \mathrm{~d}($ bar $1 \mathrm{~mm})$. f Sonication with vacuum-infiltration assisted agrobacterium-mediated transformation to induce hypocotyl for $22 \mathrm{~d}$ to obtain regenerated adventitious shoots (see Fig. S6 in 
Additional file $1 \mathrm{for}$ the original image). $\mathrm{g}$ transient GUS expression assay (bar $0.5 \mathrm{~mm}$ ). h Albino death of negative control in selective medium (see Fig. S7 in Additional file 1 for the original image). i Transgenic shoots surviving in selective medium (see Fig. S8 in Additional file 1 for the original image)

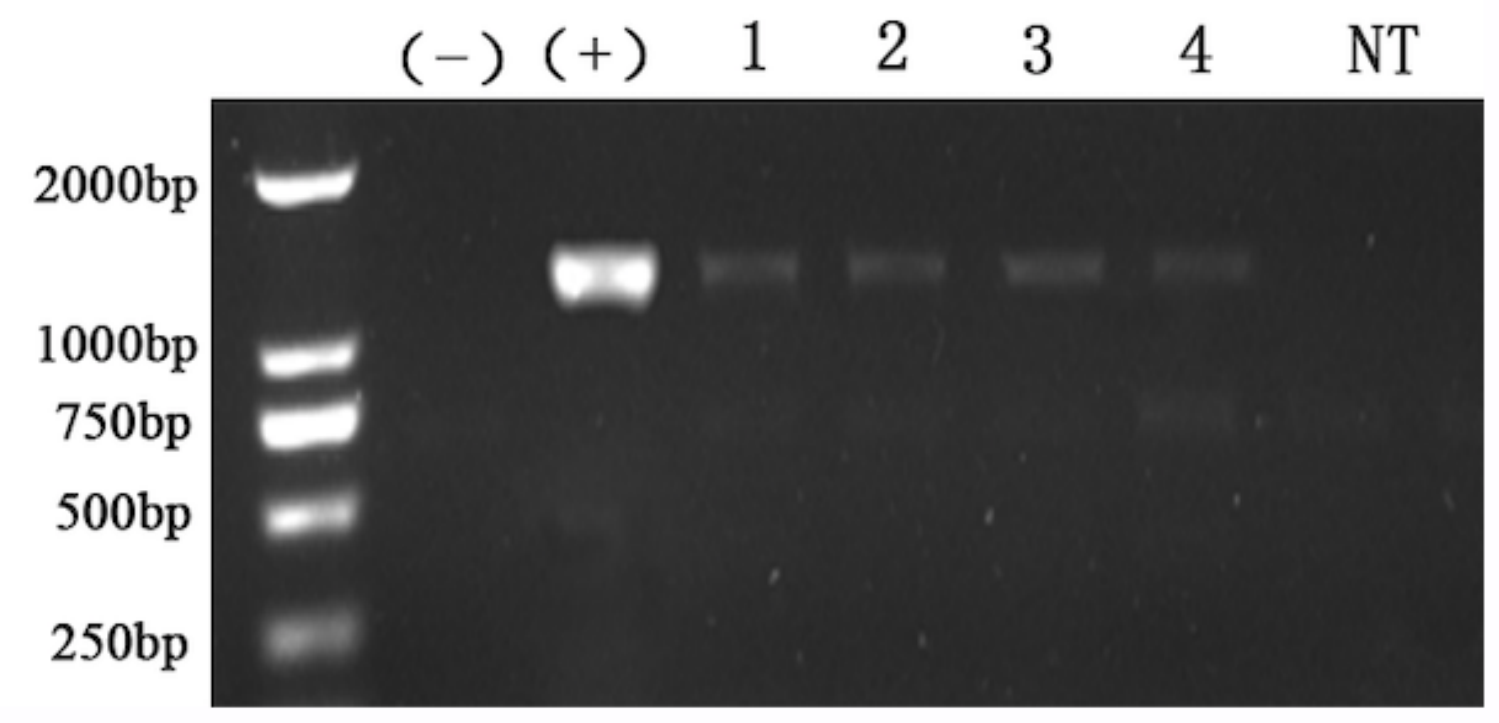

\section{Figure 9}

PCR analysis (see Fig. S9 in Additional file 1 for the original image). PCR analysis of non-transformed and transgenic resistant Fraxinus mandshurica for amplification of 1353 bp. M 2000 bp molecular marker. $₫-\rrbracket$ water control. $\rrbracket+\rrbracket$ positive control. lanes $1-4$ transgenic resistant shoots. NT negative control (non-transformed plant)

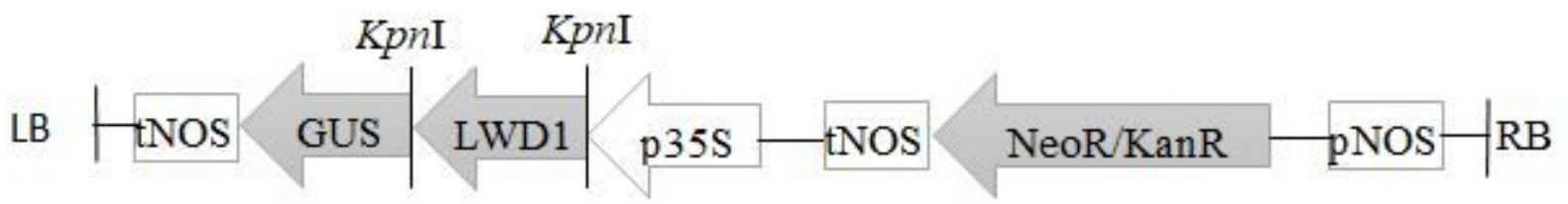

Figure 10

Schematic diagram of T-DNA regions of GUS and Proke2-LWD1 constructs. 


\section{Supplementary Files}

This is a list of supplementary files associated with this preprint. Click to download.

- Additionalfile1.pdf 